\title{
Interleukin-6 and C-reactive Protein on Admission as Predictor of Mortality in Severe COVID-19 Patients: A Retrospective Cohort Study
}

\author{
Rahayu Rahayu $^{1 *(\mathbb{D}) \text {, Winarto Winarto }}{ }^{2}$, Taufiqurrachman Nasihun $^{3}$ \\ ${ }^{1}$ Master of Biomedical Sciences, Faculty of Medicine, Universitas Islam Sultan Agung, Central Java, Indonesia; ${ }^{2}$ Department of \\ Microbiology, Faculty of Medicine, Gunung Jati Swadaya University, Cirebon, West Java, Indonesia; ${ }^{3}$ Department of Biochemistry \\ and Andrology and Postgraduate Biomedical Science, Faculty of Medicine, Universitas Islam Sultan Agung, Semarang, Indonesia
}

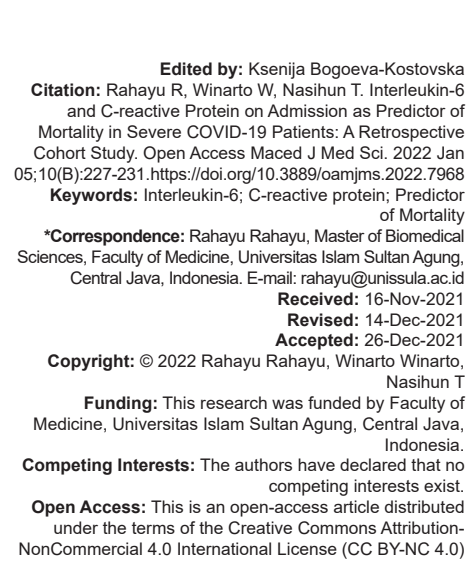

Introduction

Coronavirus disease 2019(COVID-19) has been reported for the $1^{\text {st }}$ time in Wuhan, China in December 2019 [1], which has been spread worldwide rapidly. Since March 11, Coronavirus disease was declared as pandemic by the World Health Organization (WHO) [2]. Severe acute respiratory syndrome coronavirus 2 (Sars-Cov-2) is the main cause of COVID-19 [3], [4]. In Indonesia, a total of 377,541 cases out of $2,647,094$ people tested were reported with 12,959 deaths [5] However, the predictor for risk mortality in COVID19 patients has not been understood.

Several inflammatory markers have been used to assess severity in COVID-19 patients in Indonesia. These markers include increased neutrophil lymphocyte ratio (NLR), ferritin, lactate dehydrogenase (LDH), erythrocyte sedimentation rate (ESR), procalsitonin, C-reactive protein (CRP), and decreased absolute lymphocyte count (ALC). Few studies, however, have shown these markers as predictor of mortality.
The common laboratory test for assessing severity in COVID-19 patients includes interleukin-6 (IL-6) and C-reactive protein (CRP). IL-6 has been shown to be a key mediator of the progression of cytokine storm in COVID-19 infection. Increased levels of IL-6 were positively correlated with increased viral replication and persistence of viral infection [6]. Similarly, patients with severe pulmonary infection can be early diagnosed with CRP [7].

This study aims to analyze whether IL-6 and CRPon admission can be used to predict mortality in severe COVID-19 patients.

\section{Methods}

\section{Design}

This was a single-center retrospective data analysis of confirmed cases of severe COVID-19 
diagnosed between August and December 2020 treated in an isolation room of the secondary hospital in Semarang, Indonesia. The study protocol was approved by Local Ethics Committee (No.89/EC/ KEPK/2021). Informed consent was released because of the retrospective nature of the study.

\section{Study population}

The sample size was calculated using categorical output prognostic studies. All patients aged $\geq 18$ years who had a confirmed diagnosis of COVID-19 with realtime reverse transcription of polymerase chain reaction assay (rRT-PCR) were involved in this study. The patient had at least one symptom of pneumonia such as fever, cough, shortness of breath, and plus one of the following: Respiratory distress, breathing rate $>30$ times/min or the oxygen saturation at room air $\left(\mathrm{SpO}_{2}\right)<93 \%$, treatment with oxygen therapy, antiviral drugs, dexamethasone, and anticoagulat. Exclusion criteria include autoimmune disorders, immunodeficiency diseases, malignancy, burn, referrals from other hospitals and having received therapy, and incomplete medical records. The variables studied were the levels of IL- 6 and levels of CRP on admission and the outcome was the mortality during the first 14 days of hospitalization.

\section{Outcomes and definitions}

The primary outcome was mean level IL-6 and CRP of severe COVID-19 patients on admission. The secondary outcome was cutoff of IL-6 and CRP to predict mortality during the first 14 days of hospitalization.

\section{Procedure}

Demographics, medical history, clinical data, radiological finding, and biological finding on admission were collected from medical record.

Serum CRP concentrations were measured using latex agglutination turbidimetric immunoassays (Kit C-reactive Protein NANOPIA) and the lower reference limit was $0.3 \mathrm{mg} / \mathrm{dL}$. The remaining serum was transferred in $1.5 \mathrm{~mL}$ sterile microcentrifuge tubes and stored at $-20^{\circ} \mathrm{C}$ for IL- 6 analysis. IL- 6 concentrations were measured using ELISA (Human IL-6 ELISA kit Sigma-Aldrich-RAB0306). All tests were performed according to the manufactory's instructions.

\section{Statistical analysis}

Data analysis using Spearman's correlation, a non-parametrically distribution was found. To find out cutoff points of CRP and IL-6 for severe COVID-19 patients, receiver operating characteristic (ROC) analyzes were applied. Data were analyzed using SPSS 24.0 (SPSSInc., Chicago, IL, USA).

\section{Results}

\section{Study population}

A total of 80 COVID-19 patients were involved in this study. Patients were splitted into two groups: 57 survivors and 23 non-survivors. The demographic and clinical characteristics of patients according to the outcome are presented in Table 1. The mean age of the survivor and non-survivor group was $50.74 \pm 11.2$ and $54.74 \pm 9.6$, respectively. Most of the patients were 18 to $\leq 60$ years $(80 \%)$. There was no significant difference in the number of female and male patients $(56.2 \%$ vs. $43.8 \%, p=0.304)$. There was no significant difference in the comorbid patients between the survivor and non-survivor group $(p=0.754)$. The onset of symptoms between the survivors and non-survivor group was not significantly different. The most common symptoms in severe COVID-19 were fever (80 \%), cough $(57.5 \%)$, shortness of breath $(41.2 \%)$, and weakness $(32.5 \%)$. In this study, several symptoms related to the gastrointestinal system also appeared, namely, nausea (35\%), vomiting $(23.75 \%)$, and diarrhea $(8.75 \%)$. Anosmia only occurred in $3.75 \%$ of all patients.

Table 1: Characteristics of the study population

\begin{tabular}{|c|c|c|c|}
\hline Description & $\begin{array}{l}\text { Survivors } \\
(\mathrm{n}=57)\end{array}$ & $\begin{array}{l}\text { Non-survivors } \\
(\mathrm{n}=23)\end{array}$ & $p$ value \\
\hline Age (years) & $50.74 \pm 11.2$ & $54.74 \pm 9.6$ & $p=0.138^{\wedge}$ \\
\hline$>60$ years $(n=16 ; 20 \%)$ & $9(56.25 \%)$ & $7(43.75)$ & \\
\hline $18-60$ years $(n=64 ; 80 \%)$ & $48(75 \%)$ & $16(25 \%)$ & \\
\hline Gender & & & $p=0.304^{\star}$ \\
\hline Male $(n=35 ; 43.8 \%)$ & $27(77.1 \%)$ & $8(22.9 \%)$ & \\
\hline Female $(n=45 ; 56.2 \%)$ & $30(66.7 \%)$ & $15(33.3 \%)$ & \\
\hline Comorbid\# & & & $p=0.754^{\star \star}$ \\
\hline Yes $(n=65 ; 81.2 \%)$ & $47(72.3 \%)$ & $18(27.7 \%)$ & \\
\hline 1 comorbid $(n=42 ; 64.61 \%)$ & $33(78.6 \%)$ & $9(21.4 \%)$ & \\
\hline 2 comorbid $(n=20 ; 30.76 \%)$ & $13(65 \%)$ & $7(35 \%)$ & \\
\hline 3 comorbid $(n=3 ; 4.61 \%)$ & $1(33.3 \%)$ & $2(66.77 \%)$ & \\
\hline No $(n=15 ; 18.8 \%)$ & $10(66.6 \%)$ & $5(33.3 \%)$ & \\
\hline Symptom onset (days) & $6 \pm 2.4$ & $7 \pm 3.7$ & $p=0.727^{* * *}$ \\
\hline \multicolumn{4}{|l|}{ Radiological finding } \\
\hline $\begin{array}{l}\text { Bilateral Bronchopneumonia } \\
(\mathrm{n}=71 ; 88.75 \%)\end{array}$ & 50 (70.4\%) & $21(29.6 \%)$ & \\
\hline $\begin{array}{l}\text { Right bronchopneumonia } \\
(\mathrm{n}=8 ; 10 \%)\end{array}$ & $6(75 \%)$ & $2(25 \%)$ & \\
\hline $\begin{array}{l}\text { Left bronchopneumonia } \\
(n=1 ; 1.25 \%)\end{array}$ & $1(100 \%)$ & $0(0 \%)$ & \\
\hline Length of hospitalization (days) & $10 \pm 1.7$ & $7 \pm 4.3$ & $p=0.001^{* \star *}$ \\
\hline Leukocytes (normal $3.6-11 \times 10^{3} / \mu \mathrm{L}$ ) & $6.67 \pm 3.57$ & $7.9 \pm 15.5$ & $\mathrm{p}=0.234^{\star \star *}$ \\
\hline Lymphocytes (normal $25-40 \%$ ) & $19.6 \pm 8.95$ & $14.1 \pm 7.5$ & $p=0.011^{\wedge}$ \\
\hline Neutrophils (normal $50-70 \%$ ) & $71.7 \pm 10.82$ & $77.3 \pm 7.49$ & $p=0.033^{* * *}$ \\
\hline Neutrophil lymphocyte ratio (NLR) & $3.6 \pm 4.75$ & $6.2 \pm 4.8$ & $p=0.01^{* * *}$ \\
\hline Absolute lymphocyte count (ALC) & $1313 \pm 537.5$ & $1147 \pm 564.8$ & $\mathrm{p}=0.221^{\star \star *}$ \\
\hline C-reactive protein (CRP) & $34.6 \pm 45.5$ & $57.8 \pm 58.98$ & $p=0.027^{* * *}$ \\
\hline Interleukin-6 (IL-6) & $76.7 \pm 155.27$ & $130.2 \pm 356.9$ & $p=0.028^{* * *}$ \\
\hline
\end{tabular}

The mean number of leukocytes in survivor and non-survivor group was still within normal limits $(p=0.234)$. Similarly, the number of lymphocytes in both groups decreased.

The number of neutrophils in both groups increased equally, but in the non-survivor group, it was much higher than those who survived ( $p=0.033)$.

The survivor group had a significantly lower neutrophil-lymphocyte ratio compared to non-survivor (3.6 \pm 4.75 vs. $6.2 \pm 4.8, p=0.01)$.

There was no significant difference in absolute lymphocyte count (ALC) between the two groups $(p=0.221)$. 


\section{C-reactive protein (CRP)}

The mean levels of $\mathrm{C}$-reactive protein (CRP) increased above normal in both groups. The nonsurvivor group had a lower mean CRP than the survivor group ( $34.6 \pm 45.5$ vs. $57.8 \pm 58.98, p=0.027)$. The CRP levels were weakly correlated with mortality (0.249).

\section{Interleukin-6 (IL-6)}

The mean level of interleukin-6 (IL-6) also increased in the survivor and non-survivor group (76.7 \pm 155.27 vs. $130.2 \pm 356.9, p=0.028$ ). The level of IL-6 was weakly correlated with mortality $(0.247)$.

\section{ROC curve}

The CRP cutoff was $46.45 \mathrm{mg} / \mathrm{L}$ (AUROC 0.659 (95\% Cl 0.532-0.786); $p=0.027)$. The IL-6 cutoff was $101.64 \mathrm{pg} / \mathrm{ml}$ (AUROC $0.658(95 \% \mathrm{Cl} 0.529$ $0.787) ; p=0.028$ ). CRP and IL-6 are weak mortality predictors in severe COVID-19 patients (Figure 1).

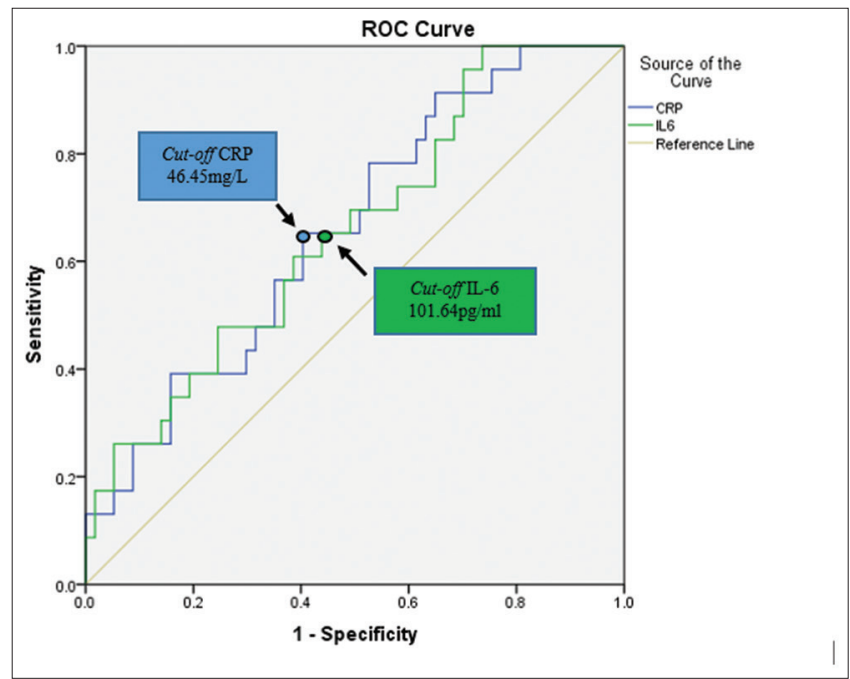

Figure 1: ROC curve and optimal cutoff CRP and IL-6

\section{Discussion}

This study focused on IL- 6 and CRP values in severe COVID-19 patients at the first admission. The main finding was that although IL- 6 and CRP were the predictors for severity, both inflammatory biomarkers were not robust predictors of the mortality.

In this study, there were more confirmed COVID-19 patients aged $18-60$ years than that of aged $>60$ years. However, there was no significant difference in outcome between survival and non-survival groups with respect to age. Old age is a risk factor for infection compared to young and middle age related to physiological changes including decreased immune system function and the occurrence of multimorbidity due to chronic disease is higher in the elderly population [8], [9]. The increase in disease progression in the elderly is associated with decreased function of $T$ and $B$ cells as well as the presence of excess production of cytokines which can lead to deficient viral replication control and a prolonged proinflammatory response that has the potential to lead to poor outcomes [10]. It has been mentioned that elderly patients with at least one previous comorbid have poor outcome [11]. In view of our results, using age to predict mortality seems to be unreliable.

There were more female (56.2\%) compared to male $(43.8 \%)$. However, this difference in number was not statistically significant $(p=0.304)$. The number of patients who survived was comparable between men $(77.1 \%)$ and women $(66.7 \%)$. In this study, there was also no difference between sexes in mortality. Up to now, the mechanisms underlying the susceptibility of different sex to SARS-CoV-2 infection remain unclear [12]. Person's ability to fight SARS-CoV-2 infection between men and woman can be affected by the immune system[13].

The ACE-2 gene is a gene linked to the $X$ chromosome. To avoid duplication, one $X$ chromosome tends to be inactive, but because the ACE2 location escapes inactivation, women have more genetic instructions to activate ACE-2 [12]. In this present study, most of the patients had comorbid. However, it cannot be the predictive factor of mortality $(p=0.754)$. A person with a comorbid had higher risk to get SARS-CoV-2 infection; however, it was not shown to be correlated with mortality. This finding is consistent with that of a study showing no difference in death rates between patients with and without comorbid [14].

This study found that the most dominant symptoms in severe COVID-19 patients were fever. This finding supports that of a meta-analysis concluding that fever was the most common symptom [15].

NLR of non-survivor group was shown to be higher compared to that of survivor group. NLR is important indicators in severe cases. Increased NLR reflects an imbalance in the inflammatory response. Thus, it can be indicator of disease severity. A metaanalysis of 15 studies concluded that the higher level of severity was associated with increased number of neutrophils or lymphocytes alone [16]. Several studies have reported that the absolute lymphocyte count (ALC) $<1.000$ cells/ $\mu \mathrm{L}$ occurring in COVID-19 patients correlates with disease severity. A similar study by Jason et al. 2020 states that the average ALC of severe COVID patients who require intensive care is lower $\left(0.8 \pm 0.11 \times 10^{3}\right.$ cells/uL $)$ than those who do not need intensive care, namely, $\left(1.4 \pm 0.15 \times 10^{3}\right.$ cells/uL $)$ $(p=0.01)$; however, in this study, it was also stated that ALC was not correlated with mortality [17]. Like in our study, there was no significant difference in ALC between survivors and non-survivors group $(p=0.221)$. 
The viral infections, inflammations, and severe trauma can be increased dramatically on CRP levels [18]. Levels of CRP correlate with levels of inflammation and concentrations of CRP levels are not affected by age, sex, and physical condition. The initial diagnosis of pneumonia can use CRP levels. The level of CRP in patients with severe pneumonia is high. The disease severity and lung lesions in the early stages of COVID-19 are having positively correlation [7].

We found that the IL-6 and CRP levels in severe COVID-19 patients on admission have increase above normal range, both those who survivor and those who non-survivor. Based on ROC analysis, IL-6>101.64 pg/ml and CRP $>46.45 \mathrm{mg} / \mathrm{L}$ were more likely to progress toward disease death. However, both inflammatory biomarkers were weak predictors of mortality.

This study had several limitations. First, this study was a single-center study, so further studies are required to include multiple centers with a bigger sample size. Second, since this study was designed as cohort study, it lacks a control group. Our finding CRP level and IL-6 level were measured only from the $1^{\text {st }}$ day of admission, so it was still biased whether the increase in CRP and IL-6 is due to the progression of COVID disease or from comorbid disease. Finally, other markers that play a role in the cytokine storm, such as interleukin (IL-1 $\beta$ and IL-10); tumor necrosis factor $\alpha$; interferon- $\gamma$ and interferon- $\beta, \quad \mathrm{CXC}$ motif chemokine ligand 10 (CXCL-10), monocyte chemoattractant protein-1 (MCP-1), and macrophage inflammatory protein $-1 \alpha$ (MIP-1 $\alpha$ ) which may affect CRP and IL-6 levels. The changes in the levels of the markers over time were not evaluated; further studies to assess their changes are needed to assess the high risk of death. Future studies are suggested to confirm this study's results.

\section{Conclusion}

Levels of IL- 6 and CRP at the $1^{\text {st }}$ day of admission were weak predictors of mortality in severe COVID-19 patients. Abetter understanding of the causes of increased IL-6 and CRP in severe COVID-19 patients is needed whether it is related to the development of COVID-19 severity or comorbid disease.

\section{References}

1. Messina G, Polito R, Monda V, Cipolloni L, di Nunno N, di Mizio $\mathrm{G}$, et al. Functional role of dietary intervention to improve the outcome of COVID-19: A hypothesis of work. Int J Mol Sci. 2020;21(9):3104. https://doi.org/10.3390/ijms21093104 PMid:3235403
2. Ortiz-Prado E, Simbaña-Rivera $K$, Barreno LG, RubioNeira M, Guaman LP, Kyriakidis NC, et al. Clinical, molecular, and epidemiological characterization of the SARS-CoV-2 virus and the Coronavirus disease 2019 (COVID-19), a comprehensive literature review. Diagnostic Microbiol Infect Dis. 2020;98(1):115094. https://doi.org/10.1016/j. diagmicrobio.2020.115094

\section{PMid:32623267}

3. Indonesian Ministry of Health. Current Situation of COVID-19. Indonesia: Indonesian Ministry of Health; 2020. p. 17-9.

4. Fang CF, Zhong M, Liu Y, Zhang Y, Zhang K, Zhen SD, et al. The characteristics and outcomes of 681 severe cases with COVID-19 in China. J Crit Care. 2020;60:32-7. https://doi. org/10.1016/j.jcrc.2020.07.003

PMid:32736197

5. Indonesian Ministry of Health. Current Situation of COVID-19. Indonesia: Indonesian Ministry of Health; 2020. Avaiable from: https://www.infeksiemerging.kemkes.go.id/document/situasiterkini-perkembangan-covid-19-23-oktober-2020-1156/view [Last accessed 2021 May 25].

6. Pacheco JM, Smoliga GR, Donnell VO, Brito BP, Stenfeldt C, Rodriguez LL, et al. Persistent Foot-and-Mouth Disease Virus Infection in the Nasopharynx of Cattle; Tissue-Specific Distribution and Local Cytokine Expression; 2015. p. 1-20

7. Wang L. C-reactive protein levels in the early stage of COVID-19. Med Mal Infect. 2020;50(4):332-4. https://doi.org/10.1016/j. medmal.2020.03.007

PMid:32243911

8. Innammorato M, Pasquariello L, Pizzirusso D, Guerrieri G, Castelli S, Pezzuto A. Age is not the only risk factor in COVID-19: The role of comorbidities and of long staying in residential care homes. BMC Geriatr. 2021;21(1):63. https://doi.org/10.1186/ s12877-021-02013-3

PMid:33451296

9. Goujon A, Natale F, Ghio D, Conte A. Age, Gender, and Territory of COVID-19 Infections and Fatalities; 2020.

10. Zhou F, Yu T, Du R, Fan G, Liu Y, Liu Z, et al. Clinical course and risk factors for mortality of adult inpatients with COVID-19 in Wuhan, China: A retrospective cohort study. Lancet. 2020;395(10229):1054-62. https://doi.org/10.1016/ S0140-6736(20)30566-3

PMid:32171076

11. Jurado A, Martín MC, Abad-molina C, Orduña A, Martínez A, Ocaña E, et al. Protein, and Lymphocytes As Key Clues from a Multicentre Retrospective Study; 2020. p. 1-15.

12. Gagliardi MC, Tieri P, Ortona E. ACE2 expression and sex disparity in COVID-19. Cell Death Discov. 2020;6:37. https://doi. org/10.1038/s41420-020-0276-1 PMid:32499922

13. Bwire GM. Coronavirus: Why men are more vulnerable to COVID-19 than women? SN Compr Clin Med. 2020:1-3. https:// doi.org/10.1007/s42399-020-00341-w PMid:32838138

14. Fang $\mathrm{H}$, Liu $\mathrm{Q}, \mathrm{Xi} \mathrm{M}$, Xiong $\mathrm{D}, \mathrm{He} \mathrm{J}$, Luo $\mathrm{P}$, et al. Impact of comorbidities on clinical prognosis in 1280 patients with different types of COVID-19 J Investig Med. 2021;69(1):75-85. https:// doi.org/10.1136/jim-2020-001555

PMid:33051358

15. Sanyaolu A, Okorie C, Marinkovic A, Patidar R, Younis K Desai P. Comorbidity and its impact on patients with COVID-19. SN Compr Clin Med. 2020:1-8. https://doi.org/10.1007/ s42399-020-00363-4 PMid:32838147

16. Vafadar E, Teimouri A, Rezaee R, Morovatdar N, Foroughian M Layegh $\mathrm{P}$, et al. Increased age, neutrophil-to-lymphocyte ratio 
(NLR) and white blood cells count are associated with higher COVID-19 mortality. Am J Emerg Med. 2021;40:11-4. https:// doi.org/10.1016/j.ajem.2020.12.003

PMid:33333477

17. Wagner J, Dupont A, Larson S, Cash B, Farooq A. Absolute lymphocyte count is a prognostic marker in COVID-19: A retrospective cohort review. Int J Lab Hematol.
2020;42(6):761-5. https://doi.org/10.1111/ijlh.13288

PMid:32779838

18. Yan Y, Liu M, LiX, Deng X, Jin Y, Qin Q, et al. Utility of the neutrophilto-lymphocyte ratio and C-reactive protein level for coronavirus disease 2019. Scand J Clin Lab Invest. 2020;80(7):536-40. https://doi.org/10.1080/00365513.2020.1803587

PMid:32804580 